\title{
Alix Barbet (éd.), La Peinture funéraire antique, ive siècle av. J.-C. - ive siècle ap. J.-C.
}

Actes du $\mathrm{VII}^{\mathrm{e}}$ colloque de l'association internationale pour la peinture murale antique (AIPMA), 6-10 octobre 1998, Saint-Romain-en-Gal Vienne, Paris, Éditions Errances, 2001, 400 p. (bibliogr., illustr.)

\section{Régis Le Mer}

\section{OpenEdition}

\section{Journals}

Édition électronique

URL : http://journals.openedition.org/assr/2302

DOI : 10.4000/assr.2302

ISSN : $1777-5825$

Éditeur

Éditions de l'EHESS

Édition imprimée

Date de publication : 1 avril 2004

Pagination : 47-112

ISBN : 2-222-96746-5

ISSN : 0335-5985

Référence électronique

Régis Le Mer, «Alix Barbet (éd.), La Peinture funéraire antique, ive siècle av. J.-C. - ive siècle ap. J.-C. », Archives de sciences sociales des religions [En ligne], 126 | avril - juin 2004, document 126.37, mis en ligne le 18 novembre 2005, consulté le 24 septembre 2020. URL : http://journals.openedition.org/assr/ 2302 ; DOI : https://doi.org/10.4000/assr.2302 
voir dans les études orientales non la découverte par les Européens de civilisations, de religions jusqu'alors peu connues ou inconnues et donc l'occasion pour l'Occident de rendre hommage et de s'ouvrir à un monde nouveau, mais au contraire la création d'un « autre », qui était du même coup jugé, réinterprété, dominé et colonisé. L'ouvrage de Said n'était pas sans mérites (ce que j'avais dit quand j'en avais fait, dans Critique, le premier compte rendu paru en France) et il a été l'occasion de quelques utiles mises en question de certains aspects de nos recherches. Mais il était aussi d'une injustice extrême et il a donné lieu par la suite, chez quelques épigones, à des absurdités. C'est précisément contre Said que s'inscrit C.A. quand il décrit et défend dans ce livre l'œuvre de découverte au cours du XIX ${ }^{\mathrm{e}}$ siècle, par les premiers «orientalistes » européens - les Sahibs de son titre -, de l'ancienne civilisation de l'Inde et plus particulièrement du bouddhisme. Que ce dernier les ait attirés plus que l'hindouisme sera peut-être considéré comme dû aux préjugés d'Occidentaux plus sensibles à son côté « raisonnable », modéré, accessible, différant en cela de l'hindouisme, plus étrange dans certains de ses rites, lié au système social exclusiviste des castes, donc replié sur luimême. Mais si C.A. axe son ouvrage sur le bouddhisme, il n'oublie pas la découverte du sanskrit, ni l'intérêt européen ancien pour le monde hindou : la Bhagavad Gita a été traduite en 1785 et on sait ce que Goethe disait de Shakuntala. Certaines observations de Hodgson, en 1835, sur les cultes de la Déesse restent valables : on ne jugeait donc pas si mal. La «Renaissance Orientale» n'est pas une vaine expression, or elle a été forgée en un temps où ne foisonnaient pas chez nous comme aujourd'hui les maîtres à penser venus de divers pays d'Asie.

Pour en revenir à C.A., si les spécialistes ne découvriront dans son livre rien qu'ils ne sachent déjà, un public moins au courant y trouvera par contre matière à s'instruire et à réfléchir - par exemple (pour prendre un cas particulier) sur le rôle qu'ont joué des Européens et des Américains dans l'évolution moderne du bouddhisme, qui n'a pris son aspect actuel que sous l'influence de l'Occident. Mais on pourrait mentionner bien d'autres points. Il y a là des récits très vivants, des anecdotes curieuses, des descriptions précises sur ce qui fut une aventure intellectuelle d'une grande importance, effet d'une curiosité désintéressée - ainsi que sur des vies le plus souvent peu banales. L'ouvrage se lit avec plaisir et intérêt. Il est, même dans son édition de poche, intelligemment illustré. Il comporte un excellent glossaire, une bonne bibliographie et un très utile index. Pertinent, agréablement instructif, c'est un ouvrage à recommander.

André Padoux.

126.35

ANDREWS (Dee E.)

The Methodists and Revolutionary America, 1760-1800. The Shaping of an Evangelical Culture. Princeton, Princeton University Press, 2000, 368 p. (annexes) (cf. supra, pp. 17-40).

126.36

BALMER (Randall).

Encyclopedia of Evangelicalism. LouisvilleLondres, John Knox Press, 2002, 654 p. (bibliogr.) (cf. supra, pp. 17-40).

126.37

BARBET (Alix), éd.

La Peinture funéraire antique, $I^{\mathrm{e}}$ siècle av. J.-C. - IVe siècle ap. J.-C. Actes du VII ${ }^{\mathrm{e}}$ colloque de l'association internationale pour la peinture murale antique (AIPMA), 6-10 octobre 1998, Saint-Romain-en-Gal - Vienne, Paris, Éditions Errances, 2001, 400 p. (bibliogr., illustr.).

Ce bel ouvrage - publié par Errance, l'un des seuls éditeurs français spécialisés en archéologie - expose les Actes du VII ${ }^{\mathrm{e}}$ colloque de l'association internationale pour la peinture murale antique (AIPMA). Le mérite de ces actes est, à la manière de ses prédécesseurs édités tous les deux ou trois ans à la suite de colloques, de nous dresser un portrait assez vivant de la connaissance sur l'étude de la peinture murale antique. Cette périodicité invite, en quelque sorte à un état des lieux mis à jour.

Le thème des actes de cette édition en particulier concerne la peinture funéraire. La production artistique dans ce domaine est, en effet, d'une rare richesse. Ainsi l'ouvrage embrasse une période allant de l'époque hellénistique à l'époque paléochrétienne, sur une ère géographique vaste, interrogeant des spécialistes de l'ensemble du monde méditerranéen et proche-oriental. On y parle principalement de l'Égypte, de l'Étrurie, du monde romain, et du monde grec bien sûr. L'ouvrage regroupe une cinquantaine d'interventions de qualité fort inégale. Les articles présentés sont en français, anglais, allemand, italien et espagnol.

Plusieurs articles regroupés pêle-mêle dans une partie intitulée "brèves », placés dans la seconde moitié de l'ouvrage, s'écartent 
malheureusement trop souvent du sujet funéraire - même si, en soi, ils peuvent être scientifiquement intéressants - et cassent le fil conducteur et l'harmonie de l'ouvrage.

Les autres articles sont très hétérogènes : les uns embrassent une large période ou une vaste aire géographique, les autres sont davantage des études techniques et pointues sur un site archéologique, d'autres enfin se développent à partir d'une thématique.

On appréciera en particulier l'étude documentée de Catherine Charatzpoulou qui fait un état de la recherche de la peinture funéraire en Grèce à l'époque hellénistique. De même l'étude de Nicole Blanc sur le symbolisme funéraire, éclairée par les conditions techniques de la réalisation du décor, à propos de tombes jumelles sous Saint-Sébastien à Rome, est fort instructive. Enfin, pour finir sur les interventions les plus marquantes, on retiendra les deux articles d'Anne-Marie Guimier-Sorbets sur les peintures de deux nécropoles d'Alexandrie en Égypte, ainsi que l'étude de John R. Clarke sur la décoration des tombes 16-22 de la via Laurentina et de la tombe 16 de l'Isola Sacra à Ostie.

$\mathrm{Si}$ A.B. entreprend un questionnement anthropologique qui éveille l'intérêt dans l'introduction, il ne faut guère s'attendre à trouver des réponses dans l'ouvrage. On trouvera quelques remarques sibyllines ici et là, montrant qu'il ne s'agit pas du premier objectif de l'ouvrage ou du colloque.

Pour la plupart de ces articles de fond, il faut souligner la grande qualité de la vaste documentation iconographique en couleur qui n'occupe pas moins de soixante-cinq pages regroupées à la fin de l'ouvrage.

\section{Régis Le Mer.}

Les Témoins de Jéhovah. Pour un christianisme original. Paris, L'Harmattan, 2003, 271 p. (bibliogr., index) (coll. «Religion et sciences humaines »).

L'ouvrage aborde le mouvement des Témoins de Jéhovah sous un angle historique (en l'inscrivant dans la lignée des groupes antitrinitaires) et descriptif, en présentant notamment leur organisation et leur situation dans plusieurs pays européens. Le livre apporte peu d'éléments nouveaux sur le mouvement de la Tour de Garde et souffre d'insuffisances de style notables, telle la surabondance de citations non référencées. En outre, la démarche globale du document est ambiguë dans la mesure où - à défaut d'avoir construit sociologiquement son objet - l'auteur ne manifeste pas de distance critique à l'égard des croyances et des argumentaires énoncés par le groupe étudié. À de multiples reprises, il reproduit et avalise sans examen les propositions (théologiques en particulier) des Témoins de Jéhovah de telle manière que l'analyse est éclipsée par le travail de persuasion.

Arnaud Blanchard.

BASLEZ (Marie-Françoise).

Bible et Histoire. Judaïsme, hellénisme, christianisme. Paris, Gallimard, 2003, 485 p. (bibliogr., index, tablx., annexes, cartes) (coll. « Folio histoire »).

Spécialiste d'histoire grecque qu'elle enseigne à 1'Université de Rennes-2 et en charge d'un séminaire à l'ENS sur «Religions et sociétés dans le monde gréco-romain », l'auteure a publié une biographie de Saint Paul (Fayard, 1991) et le Bible et Histoire qu'elle nous offre aujourd'hui est la réédition d'un ouvrage paru sous ce titre aux éditions Fayard en 1998. Très ambitieux dans son propos puisqu'il couvre une période de trois ou quatre siècles, allant des rois séleucides Antiochos III et IV jusqu'à la fin du premier siècle de notre ère, il nous offre dans une langue agréable et où l'érudition, partout présente, sait se faire discrète et accessible, le survol d'une période où religion et politique s'imbriquaient étroitement, au terme de laquelle le christianisme a pris naissance. On verra que ce dernier a puisé abondamment, et selon le génie propre de ses premières communautés, dans les structures et les institutions de la société d'alors, qu'elles soient d'origine juive, grecque, romaine. Ce qui souvent n'alla pas sans conflits, au sein des communautés elles-mêmes et avec les pouvoirs en place.

René Luneau.

BEN NEFISSA (Sarah), éd.

Pouvoirs et associations dans le monde arabe. Paris, CNRS Éditions, 2002, 179 p. (cf. supra, pp. 41-45).

126.41

BERTRAND (Romain).

Indonésie : la démocratie invisible. Violence, magie et politique à Java. Paris, Kharthala, 2002, 242 p. (coll. «Recherches internationales $\gg)$.

Politologue s'intéressant depuis déjà plusieurs années à la place de la magie dans la 